\title{
A Vibrating Body: Sound in Redefined Space and Time
}

\author{
Luís Cláudio Ribeiro \\ Lusófona University, Lisbon \\ luis.claudio.ribeiro@ulusofona.pt
}

Received 18 March 2020; accepted 20 September 2020; published 17 December 2020.

\begin{abstract}
What was at stake in the nineteenth century was not only the impulse towards light (in the case of photography), but also towards sound, which had its own matrix and devices, associated with another form of culture. The culture of the senses, whether as memory or as experience, was, at that time, a crucial element in a new perception of reality. This new perception was revealed in the rise of artistic works where the dweller of the urban or rural environment was part of the narrative. Sound culture started to develop from the nineteenth century onwards, when technology made it possible to reproduce what was invisible and to conduct research in invention centres and laboratories. Hearing and listening became crucial parts of the one's access to reality and individual education. Sound established the relation between technology and the subject, increasingly uniting communities around the acoustic experience.
\end{abstract}

Keywords: sound; technology; auditory; culture; city

The sound must seem an echo to the sense

(Alexander Pope - Sound and Sense)

\section{The Cultural Emergence of Sound Culture}

Little over two hundred years ago, what we now understand by "sound culture" emerged as a new constellation of knowledge, fostered by a constantly mutating anthropological and sociological space, affected by technology, which made public what once belonged to limited groups. The modernity of sound began with the subtle shift from visual landmarks to a technology in which sound was desirably visible and carried meaning. From Acoustics (1802) by 
Ernst Chladni to Morse's telegraph, the vibrating element of what is alive gradually attracted research, which involved language itself as well as the modes of its use and deprivation, such as deafness ${ }^{1}$.

What was at stake in the nineteenth century was not only the impulse towards light (in the case of photography), but also towards sound, which had its own matrix and devices, associated with another form of culture. The culture of the senses, whether as memory or as experience, was, at that time, a crucial element in a new perception of reality. This new perception was revealed in the rise of literary and artistic works where the dweller of the urban or rural environment became the focus of the narrative.

Sound culture started to develop from the nineteenth century onwards, when technology made it possible to reproduce what was invisible and to conduct research in invention centres and laboratories. Hearing and listening became crucial parts of one's access to reality and individual education. Sound established the relation between technology and the subject, increasingly uniting communities around the acoustic experience.

From Chladni to Helmholtz, from Bell to Edison, or from Martinville to Charles Cros (to name just a few), vibration and resonance became crucial to the description of a new kind of knowledge and fostered the invention of technical objects which would serve a mainly urban population. These new devices affected humans' relation to nature and caused the fragmentation of the auditory experience.

The replication of reality, which was both the cause and effect of the mediatization of life that we will observe already well into the twentieth century, happened by the separation of the senses of sight and hearing, in particular. It affected and enabled some arts and technologies, such as the radio and silent film. Then it became possible to reunite sound and image by tuning and synchrony ${ }^{2}$ : the two concepts used in media ecology. To these we must add resonance, when the body and its materialities become central to the recognition of old and new connections between the living and their environment.

\footnotetext{
${ }^{1}$ The researcher who contributed to the in-depth study of the relation between speech and deafness was the father of the inventor of the telephone, Alexander Melville Bell, with his book Visible Speech: The Science of Universal Alphabetics, 1867. Other studies were published in the first half of the twentieth century, for example: William Henry Henslowe, The Phonarthron: or the natural system of the sounds of speech, in 1840.

2 "Sintonia", in the Latin languages (tune or tuning, in English), derives from the Greek word "syntonia" meaning a tension exerted by the body, an undertaking or intense effort. It is then the correct way of being in harmony with the sense and the presence of the other. When applied to a medium, "sintonia" is the accordance of frequencies between sender and receiver. In English, the word "tune" or "tuning" fosters the agreement between the medium, the sender and the receiver. These words no longer take shape within the scope of "on-site", rather they partly annul the space and time necessary to the live interaction between entities. Also, the German word "Stimmung", as so well phrased by Leo Spitzer (Classical and Christian Ideas of World Harmony: prolegomena to an interpretation of the word "Stimmung", 1963) may well mean atmosphere, humour, harmonious unity, chord or tuning. Most of these meanings of Stimmung are connected to sound, since Stimme means voice.
} 
Through technology, the modernity of the nineteenth century rebuilt part of the subject's sensitivity. This process was aptly described by Arthur Rimbaud ${ }^{3}$ and in Hermann von Helmholtz's research: "the emergence of a new position for the listening person, namely a position of doubleness as both object and subject, simultaneously transparent and opaque to knowledge" (Steege, 2012, p. 44). Studies on the ear and sound in the first half of the nineteenth century contributed to the formulation of a theory of sound and, in particular, to the study of the organ of hearing: from then on, the ear started to be seen as a plastic and malleable organ, capable of being trained and educated (Steege, 2012, p. 54). This presupposes a new "listening regime". It is this regime, and its different operations, that will be essential to understanding recorded music or the sound fragments, "objects" which comprise the soundtrack of a film, a video or a game - or even humans' wandering territory and its soundscape. "Fragmentized" by urban planning and, later on, by the media, the urban space needs sound to reorganize what is now mostly hidden or visually inaccessible to a walking individual. The aural experience, emerging from this new listening mode, uncovers pasts and futures in the sublimation of the present space.

Thus, in the first patents and in the reception to new sound recorders and players, the emphasis put on the auditory experience presents itself as an alternative to logocentrism or ocularcentrism. The ear is promoted to the status of a reactive, operational organ in the construction of our ontological space. Sound thus becomes an "epistemic object", where each function is established and can be sustained: the voice, the word and the pitch; harmony, sound and sense; world, living and place. Sound is not just what we hear from a particular event; it is a structure defined by space and time and, then, also by the human with his or her cultural background and action, artistic or otherwise, performed on the sound element.

\section{The Otological Media}

We mentioned the two secrets to be uncovered in the nineteenth century: light and sound. Neither of these elements can be fully acquired without the intervention of technology. Even so, light remained connected with opacities. What we see is merely the reflection of light on material objects. Now with sound, we almost fully manage its manifestation. Be it in theories of Martinville, in Edison or those who followed, sound is, in the recording and reproduction technology, taken at its face value. Unlike light, sound does not need the electrical and neuronal illusion to acquire elements of its qualification, such as volume, timbre and duration. Albeit invisible, the sound object is formed in distinct and measurable qualities, depending on the source and the propagation medium. Sound is not a stable object, as are, partly, the elements of visual culture, but rather an object in motion and in a medium which imbues it with

\footnotetext{
${ }^{3}$ In the same letter (Lettre de Rimbaud à Paul Demeny - 15 May 1871) in which Rimbaud assumes the break/deep separation from a singular "Car je est un autre" [Because I is another] also highlights others: "Le Poète se fait voyant par un long, immense et raisonné dérèglement de tous les sens". [The Poet makes himself a visionary through a long, immense and reasoned disorganization of all the senses].
} 
instability ${ }^{4}$. Still, this instability does not mean that sound fades away with its ghost (the more or less visible sound producer). Whenever we hear, "sounds are perceived to be relatively stationary with respect to their sources" (O'Callaghan, 2009, p. 30). All this is related to the time preceding phonography, the medium to uncover sound. For many years, sound was an element of entertainment in the streets of European cities, as would be the case in the 1920s with radio, and later, with portable devices of sound reproduction. To understand this aspect, which is still relevant in the twenty-first century, we might need to remove the machines which produce sound, such as computers, and speak of the mechanical medium as a complement of handmade instruments; it is from this source that what we understand as mechanical music emerges. The way those "speaking machines" operated was not understood by people, especially because the city environment was sonically polluted by street artists: there are thousands of documents on the noise produced by street musicians, mainly in English cities (cf. Picker, 2003). The transposition of musical tones into material metallic bumps and the separation of these bumps on a surface, a space in which time is defined by the mechanical path of the pick, is a revolution only possible at an historical moment when ideas, utopias and concepts could manifest themselves in materialities. By this, part of the symbolism that had founded the western world was gradually being lost.

These new devices were mechanical objects that had in them all the magic of the ancient musical instruments without the complexity of interpretation. A mechanical object replaced in its function an orchestra, which would reproduce and disseminate music and sounds: since then, musical reproduction has been portable and technical.

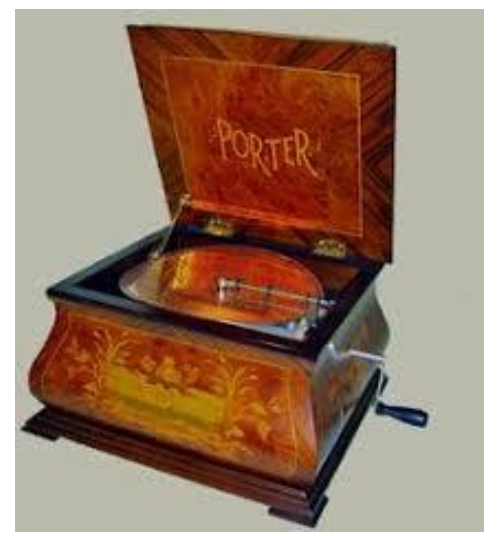

Fig. 1. Mechanical Music Box (Porter Music Box Co.)

Resonance is another key concept that was re-discovered in the area of sound reproduction. Well before Bell's and Helmholtz's experiments and treatises - the former on the telephone and the latter on musical patterns and the synthesis of the human voice and resonators, the

\footnotetext{
4 " [S]ound is motion of that which is capable of being moved in the same manner as things rebound from smooth surfaces when struck sharply against them”, Aristotle, De Anima, p. 59 (420a).
} 
word "resonance" referred to the possibility of repetition and, at the same time, to what diverges from nature. Someone singing at a piano gave this instrument the power to produce sound through its cords by resonance. Thus, from mechanical music, material and physical, we move to the possibility of sound resonating on objects, be it on a layer of blackened paper, be it on plastic or vinyl and on our very bodies. Moreover, this idea of resonance can also be observed in other arts. Actually, the sound produced by the urban environment - the environment we inhabit, increasingly cosmopolitan and diffuse - contains both the elements of aggregation and dissolution: aggregation to the place because of it sonority; and dissolution as a result of the overproduction of sound sources or of (re)production technologies, which link the sensory organ to the medium. Still, the sound quality - when it is to become an integral part of our experience - remains in us, since it carries life to the listener's mind. And thus the identity of every individual involves hearing him/herself also from the others or from the resonating surface of the world, which is a part of what we understand as consciousness.

Resonating is, first, a material application, to be later a circumscribed or prolonged intuition. Sound is the circulation of life and movement, limited by the emergence of machines which do away with the substantial part or the total energy of the human body and express sound in different materialities.

Easily - and the path that science took in the nineteenth century was an easy one - inventions left the laboratories and experimentation centres to settle in shops and people's homes; thus an industry was born which would be later criticized for fetishization and the transformation of music into a commodity. What was desired to be stable and unmovable - for example, composition and melody - earned, by virtue of technology, a new shape and a new identity, moving closer to what we think of as sensory culture nowadays. In its ethnographic trail, the sensory culture became, in the twentieth century, a model of perception and identification of the place and its populations, even if sometimes misrepresented or mischaracterized. The sensory culture led to an awareness of what can be changed in the urban space, not to restore but rather to renovate the place of belonging (a sense of place).

Sound resumed its essential place with the possibility of recording it on the magnetic tape and editting it in a studio, which was already done in film. The 1930s and 1940s would then be marked by the conviction that the transformation of an academic science into an experimental one and its move from the laboratory to the auditorium had not been done in vain. What needs emphasizing is that this emergence contributed to the development of remote communication technology, and fosters a close relationship between contents and communities, contents which, for the most part, are dislocated, by transmission, in time and in space.

Sound thus becomes a commodity, not because it became popular, but because it always belonged to the popular culture of the senses: it gramophonized itself. This allowed us to know what others think of their melodies and, better yet, how to produce and listen to them without ever having attended a music conservatory. With this move other developments followed: the education of the ear, attention to sound materialities and a material ear (to use here Helmholtz's terminology) and the connections between them. These gradually met in the reproduction of time and space, long before electronic production. 


\section{The "Gramophonization" of the World}

In the age of technical reproduction, sound technologies were merely a logical path of development for a subject constantly searching to unite fragments and, in them, cultures. The human body, now technologized, gained a different rhythm and was ready for different media and for their hybridity. It was a body ready for the experience of listening to the radio and watching film and later television and video. The thirty golden years of the nineteenth century, from 1860 to 1890, are then repeated from 1920 to 1950, with the growing use of radio, sound and image synchrony, the development of television research and new recording media, such as magnetic tape, as well as new radio studio technologies. The two world wars also forced people to rethink the place of the mortal body in the world and in the urban environment which accommodated it, as well as to consider other possible lives from what the media and technologies were bringing about. It was possible to love at a distance and it was possible to reflect on that distance. And that is what gave rise to all we know of the second half of the twentieth century, in artistic, aesthetic and technological terms.

We were finally snatched from an ontological resting place, from the ear, and engaged in the action of building a new way of being, or at least of darning the huge holes which modernity left in plain sight. This process of reconstruction will resonate with the vibration of the nineteenth century. The magnetic tape or the disc are nothing more than remaking time, both for those who create and those who listen. On different levels, we know that the Bergsonian durée, or a cultural and ethical memory, finds expression in another time.

Little by little, researchers' attention shifted from the natural reality to the new technical objects, the inheritors of the "talking machines". What had arisen as a scientific experiment (Helmholtz) and then formed the basis of devices for recording the human voice and communicating it over a distance (first with Scott de Martinville, and then with Cros, Edison and Bell, among others) evolved from the functional deviations of these recording machines, conceived for a "natural stenography" (Martinville) of sound to help the deaf or recording the human voice. In just a few years, the human voice gave way, partly, to music, and music gramophonized itself under the empire of an inter-net ahead of its time: radio. The changes in listening, brought about by this attention to the sonic fragment, fostered easy contamination, like a "sympathetic vibration" of the instruments, of the "spiritual ear" (Helmholtz). What was heard in the gramophone and especially on the radio was transformed into a hybrid of genres which, well into the twentieth century, ranged from rock ' $n$ ' roll to hip-hop; with these music genres, street sounds were retained and expected to be heard. Their sound ambivalence was brought into the studios, which can today be heard in a large part of music production. The street that listens to its own sounds in media terms is also a source of production and creation.

The sensory culture, which was located in sounds, now goes global. And thus, popular culture became more dense and found new cult spaces which were no longer merely physical. They were promoted by materialities invented to give total expression to a body which, was split both from its - now exterior - voice and image. This new body could process the sounds produced first in recording media, in the magnetic tape, and then in sound production, in an analogue or digital studio. Sound is now, paradoxically, a kind of glue that unites all spheres, including the very semantic noise of the world. 
A significant change in the forms of reception of the musical work appeared. Whereas in confined spaces, the sound reception would always deserve the attention given to something out of the ordinary, like an aesthetic activity, with the decentralization of the broadcast of the musical work, the distraction (Benjamin and especially Adorno) makes the musical composition a part of a soundscape, which we can all hear but which we listen to only with intent. The house was then filled with sounds affected by "schizophonia" (Schafer, 1977, p. 88), characteristic of the new recording and reproduction technologies. Just as we live with natural and human sounds, we also start filling life in space with the music coming from the record player, from the radio or from the soundtrack of film, television and the internet. It thus becomes part of the daily pursuits.

Advertising of the new domestic appliances for sound reproduction used this new element, incorporating by "personification" (Gitelman, 2006, p. 25) the talking machines as part of the family circle and, in the artistic scope, as musical instruments. Indeed, the slogan used by Philco, the American company founded in 1892, was "a musical instrument of quality": "singers who have never been particularly popular in the household become favourites overnight [...] With Philco the family hears the singer's voice just as though the artist were present in person [...] Philco is the only radio scientifically designed as a musical instrument" (Goodman, 2010 , p. 20, an advertisement run in December 1932). From the laboratory to the streets, from the streets to the studio, and from the studio to our ears, the sound object became a matter of resonance and an integral part of the construction of the subject, even in distraction ${ }^{5}$. Distraction $^{6}$ can thus be seen as "part of the modern condition - enabled by the revolutionary technology of recorded and broadcast sound that allowed ordinary people to choose to accompany their lives with talk and music from elsewhere" (Goodman, 2010, p. 45).

What was happening in the concert hall or outdoors is not without importance in that dispersion of sounds. Reduced listening ${ }^{7}$ (écoute réduite), so significant in the new music that came out of the studio, in the case of Pierre Schaeffer, becomes a way of, at any moment, wanting to feel and understand part of a sound composition. Recording technology has allowed, as when reading literature, to discontinue time and start the moment when sound is heard from its technical source, as a contingent object. This reaction will be important, years later, when

\footnotetext{
${ }^{5}$ Actually, what Kittler thought on Freud as the one who, "determined to sacrifice his knowing subjectivity, produces a transposition of media onto himself: his ears become a telephone receiver" (Kittler, 1990, p. 284) can be thought of any one of us these days, merely changing the name of the reception device, or not.

${ }^{6}$ The word distraction, from the Latin "distraction", refers back in its root to a type of behaviour in reception and use of equipment which would be fundamental in the twentieth and twenty-first centuries: the idea of separation, division of the active unity in daily life, was already characteristic of hearing regarding human and environmental sounds; hence the verbs listen and hear with different uses concerning hearing acuity and subject's intent: the former generates tension from the inside out, the latter a tension in the opposite direction (Jean-Luc Nancy in "À l'écoute" (2002) /Listening, 2007, in the English translation).

${ }^{7}$ Regarding "reduced listening", Chion elucidates: "In this instance, listening makes willful and artificial abstraction from the cause and from meaning — and I would add, from the effect — in order to attend to sound considered inherently, that is, for those sensible qualities not only of pitch and rhythm but also of grain, matter, form, mass, and volume. In relation to the other forms of listening, it is reduced listening that takes a sound, whether verbal, "musical", or realistic, as an object of observation in itself, instead of cutting across it with the aim of getting at something else. This is an activity that is strictly voluntary and cultural" (Chion, 2016, p. 170).
} 
the notion of synthesis developed in the field of chemistry and philosophy in the eighteenth century and in the artefacts of the nineteenth century, will be integrated into new instruments, strange devices (Pinch and Trocco, 2002) of sound production: synthesizers.

The way these new instruments operated can be only understood by looking at the changes in listening which occurred since the invention of the phonograph and of a new perception of the music sound, which means, also, a substantial change in the notion of body and its environment. The change in listening enabled the ear of the sound matrix (which comprehends our sound imaginary) to conceive of other sounds which were not available in the natural and human environments. The fragmented body heard first and then wanted to make those sounds that occurred in that new sound matrix. To produce them, new instruments had to be invented, very different from the classical range of musical instruments. These new instruments would give to the product, the sound designer and the artist the desired sound element.

Sonic art and sound events have decidedly become mental experiences. And sound envelops the city, resonating in it and in the bodies, from different media and devices, going forward through avenues and alleys, always promoting an experience which is, simultaneously, tactile and auditory. The houses and the cities are today the deposit of a sound alluvium which "manufactures" our daily perception of time and space. It is very different from the pre-phonographic and mechanical ages, when people lived in urban spaces still close to oral communication, still far from the large avenues, and from the vast population flows from the rural areas into the large industrial and urban spaces - spaces created from a visual aesthetics and from a culture which had its symbolic foundation in the sense of sight.

While the aural experience as such does not qualify space and merely isolates the sound source, sound results from the characteristics of the phenomenon which produces it (the qualities of the source, the space between it and the ear and the listener him/herself). Therefore, this space must be thought of in terms of an aural experience (even though at its roots also lies a visual one). The aural experience represents a sense of presence, even if, in an acousmatic sound, it is a "ghost", not redundant but rememorized or entirely new in the sound matrix that composes its listeners. Only thus is it possible to acquire a kind of "new imagination" which will erect a passage to the place of belonging, be it in the rural (bearing nowadays media features of the cities) or in the urban environment.

\section{The Sound and the City}

The invention of the camera and the phonograph "miniaturized space" and set a new notion of time. Whereas, in the case of technical image, engraving and painting had already established the foundations of representation, with the phonograph time imploded and settled, not on itself but rather where it is shown in hearing. The effects of recorded and reproduced sound, first as impression, a calligraphy of the voice (Martinville, Bell and Edison), and then as a recording of other sound productions, both natural and human, have deposited themselves - almost from the beginning - in the gaps left by the fragmentation of linear time and space which guided the flow of life. 
The partial loss of the unifying effect of visual symbols and their representations (from the religious element to daily ethics) has created open spaces which might have been filled by an ever-listening ear and, as already stated, transformed into a place of new experiences. Sound has become part of these spaces, intended to knit together fragments, partly annulling the actual collapse of space and time as ancestral units which used to qualify life in the past.

Towards the end of the nineteenth century, people were already aware of the importance of sensory experience and its hybrid nature due to an impressive amount of sound and image spectra surrounding them. This belief was consolidated throughout the twentieth century by paying attention to new "routes" and "passages" which the urban experience could produce. This was accompanied by a reformulation of the urban design and the incorporation of new ways of listening.

We are aware of the importance of sight to our understanding and the human relationship with nature and technology: idea, intuition and theory arise from the necessity to abstract and suspend individual objects from what seems an inaccessible reality for our understanding. With the invention of the technical recording and reproducing of objects, a new way of building reality is established. While visual culture is attached to measurability, quantification and the material quality which occupies a particular space, with the repetition of a sound, always already coming from an event, a deviation towards the in-between bodies is "created". What is of interest here is what does not occupy space but rather is space: the in-between materialities or states where sound is propagated. This is what Carpenter and McLuhan (1960) called "Acoustic Space" (Schafer, 2007), which later had different semantic implications in the fields of physiology, acoustics and ecology, depending on the area studied.

In this acoustic space, which also contains electricity, the body is honed and fine-tuned (we need but think of the music genres of the post-Second World War time). This is an "in-between" place, which can be that of a passage, as in the case of Heidegger's "Stimmung" (1996). The body is not merely a receiver but also an agent which is involved in recreating this "empty" space, between bodies or between materialities. And because the skin that covers the whole body, including the ear, is the first organ, it does not become an obstacle but adapts itself to sound by resonance. The body is a percussion instrument and, as many of these instruments, it was, and partly remains, an instrument of skin and bones. Its electrification by contamination, by the medium or by electricity itself (a new sympathetic resonance), has transformed it too, especially in the last decades, into a transistor and transductor of an urban life. This urban component surfaces even in the midst of the rural environment, from which we cannot stray too much even if we are willingly walking towards a natural immersion: as an object, the sound fragment has become part of the realization of time and space and a new access route to a reality subjugated by screens (from the landscape to the inside of the houses we inhabit).

One of the daily practices ${ }^{8}$ which were gradually lost or changed in the second half of the twentieth century was that of urban wandering. Walking, which nowadays has returned but still in small sections of the population, has given way to travel by car, bus, train, plane or, at present and in large cities, to other means of self-mobility. In all of them it is possible to

\footnotetext{
${ }^{8}$ I am using the terminology of French sociologist and historian Michel de Certeau: The Practice of Everyday Life (1988).
} 
observe, from the emergence of the car stereo in the 1950s, an elimination of sound or installation of filters to the urban soundscape with the intensive use of portable devices of sound and/or visual reproduction ${ }^{9}$.

The "prose of the world"10 has gradually changed due to the imposition of new times and spaces, as a result of the media ecosystems. What used to be an organ of natural percussion, the skin, the body, was invaded by beats which did not belong to the skin of the city. These sounds are entirely autonomous or merely use elements of the technical or urban rhythm. With this movement we lose in part the possibility of reconstructing and renewing place, as well as its daily life - we lose an important part of language and memory.

There is no intention here to make the subject return to another time and space, but rather to help him/her take root in another language and memory, on the basis of attentively listening to that place. To this end, it is necessary to change how we perceive the world, replacing, whenever possible, linearity with circularity (vision with hearing). Thus, we produce ghosts and crave their sense, as a device which promotes an imagination that will transform reality into a space in continuous construction and deconstruction:

Memory mediates spatial transformations. In the mode of the "right point in time" (kairos), it produces a founding rupture or break. Its foreignness makes possible a transgression of the law of the place. Coming out of its bottomless and mobile secrets, a "coup" modifies the local order. (Certeau, 1988, p. 85)

The observer also becomes his or her own audience: we are what we hear in us. It thus becomes urgent to enhance practices which do not merely think "geographies of visual constructions". By becoming part of this audience, we earn another "topographical system" and thus produce another space. This means that the set of relations developed on the sound stage will give rise to new means of expression for the city.

What has been broken step by step throughout the past years is firstly, the old definition of "space" which was, simultaneously, "physical" and "geometrical" (Certeau, 1988), drawn into the city by the urban planner, and secondly, the existence space where Man was fulfilled. What sound wandering incorporates (by wishing to put an end to that split) is an "anthropological" space, defined by resonance and then by one's deduction concerning this resonance. The everyday experience becomes, therefore, more efficient and enables us to incorporate a segment into the general constellation: "treatments of space", to use the terminology proposed by Certeau (1988, p. 122). And these treatments of space must always be undertaken with the inclusion of narratives that inhabit the place or of old memories, both auditory and visual. This will enable a better description in time. This path is based on the research on the relation of the city with its sound, and how space is constituted for an aural experience, which is increa-

\footnotetext{
9 "The panorama-city is a 'theoretical' (that is, visual) simulacrum, in short a picture, whose condition of possibility is an oblivion and a misunderstanding of practices. [...] It is as though the practices organizing a bustling city were characterized by their blindness" (Certeau, 1988, p. 93). To which we add, in recent times, a certain type of deafness.

${ }^{10}$ Title of the work by Maurice Merleau-Ponty, 1969.
} 
singly closer to the human body. And, to that end, we must not forget that the totality of this experience is a continuous reorganization of explicit or implicit sound fragments.

A sound fragment is considered to be part of a unit which composes the soundtrack of a film, a play, a song or a soundscape. The fragment was elevated to an aesthetic category, especially after the end of the nineteenth century. Yet, only much later, particularly after the First World War, did the fragment become part of a mutating act of listening.

With the use of recent recording and playback technology, the sound segment that passes from the microphone to the speaker trains our ears in listening to distinct units of meaning. The possibility of putting together sounds from different sources, which favoured, in the case of film and radio, the auditory immersive capacity, made those sounds autonomous, transforming them for all matters and purposes into phenomena that occur as sound objects.

Our ears and our sound matrix have gradually adapted to these changes, both in listening to a sound medium and in artistic activity, such as new music and sonic arts. Thus, "to synchronize" was a verb that exerted great influence on the new reproduction media, denoting an attempt to place - in the same space and time - an image and its sound. However, at the end of the nineteenth century the great narrative units, even in literature, were becoming extinct as a result not only of technology, but also of changes in human behaviour regarding nature and art. The implosion which took place in these great narrative units, defined by time and space, can be seen even today in art and especially in the materials which use sound as the primary means of expression. Synchronizing fragments of images and sounds, an action which might seem odd in the previous centuries, became a crucial part of the process of creating human representations.

The first radio and the first talking film were the most active media in the dissemination of a distinct musical time signature and in joining the screen image with naturally or artificiallyproduced sounds. Broadcasting distinct genres, some moving towards hybridity, which would be crucial in the music of the second half of the twentieth century, as well as joining sound fragments to image enabled the adaptation and the creation of a listening experience so far unheard of. We become composites of differentiated images and sounds which at any moment, and in each person, develop in other senses than listening: "Media archaeology is not just a human mode of understanding technology, it is also a form of technical perception in which the technological device itself turns into a listening organ" (Ernst, 2016, p. 31).

Indeed, the implosion of the narrative connected to a linear development of time contaminated the technical objects of recording, reproducing or transmitting, linking them to phenomenal structures - conceptual resonance in the process of becoming, in constant differentiation from the time of listening to or seeing. As Walter Murch tells us,

the most successful sounds seem not only to alter what the audience sees but to go further and trigger a kind of conceptual resonance between image and sound: the sound makes us see the image differently, and then this new image makes us hear the sound differently, which in turn makes us see something else in the image, which makes us hear different things in the sound. (1994, p. xxii) 
The use and optimization of the microphone rendered the surface of the world denser, just like an image of the skin under the microscope. It is for this reason that it is possible to understand not just other paths to access reality through sensory culture, but also to find passages to a new ontological resting place so necessary to the construction of an urban time which does not forget the origin of the city and its communities.

\section{Conclusion}

With the appearance of recording and sound reproduction devices in the last century the notions of identity, territory and culture have changed. Identity, seen as a form of uniqueness, has been partially diluted in the aspirations of community and society as well as in the modes of its constitution. Identity, territory and culture are now constructed, not so much through the individual relation with experience and its development, but through the different layers that constitute our daily lives, united in constant turmoil and progress. The human in the contemporary world is a complex construct that escapes determination through the modern concept of an individual. It is placed at a distance from the original by the intensive use of technology and in a rupture, perhaps irreversible, from the natural foundations of knowledge and experience. The use of technology has always involved various forms of mediation that have progressively removed us from a natural perspective.

The hybridity of modern forms and the contamination of structures and categories transformed space into a stage of an endless spectacle, especially in the urban context. Through history and literature, as well as through all existing images, we realize that the territory has been occupied by human presence and ambulation, forgetting in recent times to inscribe the radical set of changes. The urban space is now an extension of the radial space of technology and behaviour.

In this sense, and because acceleration is a vital element of the contemporary, it is important to understand the territory that has collapsed, what is left and its future. The new means for recording and reproducing sound have allowed us to make tracings, unions, while constituting layers that can represent cultural and historical elements important to the urban communities ${ }^{11}$.

\section{Funding}

This work has been supported by the FCT-Portugal grant, the project PTDC/COMCSS/29096/2017.

\footnotetext{
${ }^{11}$ To be analyzed and described in Aural Experience, Territory, and Community (project PTDC/COMCSS/29096/2017 supported by FCT-Portugal and under development at CICANT, Universidade Lusófona, in Lisbon).
} 


\section{References}

Adorno, T. W. (1941). On popular music. Studies in Philosophy and the Social Sciences, 9, 17-48.

Aristotle. (2008). De Anima (R. D. Hicks, Trans.). New York: Cosimo.

Bell, A. M. (1867). Visible speech: The science of universal alphabetics. London: Simpkin, Marshall, and Co.

Benjamin, W. (1992). Sobre a arte, técnica, linguagem e politica (M. Alberto, M. A. Cruz, M. L. Moita, Trans.). Lisboa: Relógio d’Água.

Benjamin, W. (2000). Oeuvres. Paris: Gallimard.

Carpenter, E. \& McLuhan, M. (Eds.). (1960). Explorations in communication: an anthology. Boston: Beacon Press.

Certeau, M. de. (1988). The practice of everyday life (S. F. Rendall, Trans.). Berkeley, Los Angeles: University of California Press.

Chion, M. (1994). Audio-vision: Sound on screen (C. Gorbman, Trans.). New York: Columbia University Press.

Chion, M. (2016). Sound: An acoulogical treatise (J. A. Steintrager, Trans.). Durham, London: Duke University Press.

Chladni, E.F.F. (1809). Traité d'acoustique. Paris: Chez Courcier.

Corbin, A. (1994). Les cloches de la terre: Paysage sonore et culture sensible dans les campagnes au XIXe siècle. Paris: Albin Michel.

Ernst, W. (2016). Sonic time machines: Explicit sound, sirenic voices, and implicit sonicity. Amsterdam: Amsterdam University Press.

Gitelman, L. (2006). Always already new: Media, history, and the data of culture. Cambridge: MIT Press.

Goodman, D. (2010). Distracted listening: on not making sound choices in the 1930s. In D. Suisman $\&$ S. Strasser (Eds.), The sound in the age of mechanical reproduction (pp.15-46). Philadelphia: University of Pennsylvania Press.

Heidegger, M. (1996). Being and time: A translation of Sein und Zeit (J. Stambaugh, Trans.). New York: State University of New York Press.

Helmholtz, H. von. (1895). On the sensations of tone as a physiological basis for the theory of music (A. J. Ellis, Trans.). London, New York: Longmans, Green, and Co.

Henslowe, W.H. (1840). The phonarthron: Or the natural system of the sounds of speech. London: J.G.F \& J. Rivington.

Kittler, F. A. (1990). Discourse networks 1800/1900 (M. Metteer \& C. Cullens, Trans.). Stanford: Stanford University Press.

Merleau-Ponty, M. (1969). La prose du monde. Paris: Gallimard.

Murch, W. (1994). Foreword. In M. Chion. Audio-vision: Sound on screen (C. Gorbman, Trans.) (pp. vii-xxiv). New York: Columbia University Press. 
Nancy, J-L. (2007). Listening (C. Mandell, Trans.). New York: Fordham University Press.

Nudds, M., \& O’Callaghan, C. (Eds.). (2009). Sound and perception: New philosophical essays. Oxford: Oxford University Press.

O'Callaghan, C. (2009). Sounds and events. In M. Nudds, M. \& C. O'Callaghan (Eds.), Sounds and perception: New philosophical essays (pp. 26-49). Oxford: Oxford University Press.

Picker, J. M. (2003). Victorian soundscapes. Oxford: Oxford University Press.

Pinch, T., \& Trocco, F. (2002). Analog days: The invention and impact of the Moog synthesizer. Cambridge, London: Harvard University Press.

Rée, J. (1999). I see a voice: Deafness, language and the senses - a philosophical history. New York: Metropolitan Books.

Schaeffer, P. (1966). Traité des objets musicaux: Essai interdisciplines. Paris: Seuil.

Schafer, R. M. (1977). The tuning of the world. New York: Knopf.

Schafer, R. M. (2007). Acoustic space. Circuit, 17(3), 83-86.

Spitzer, L. (1963). Classical and Christian ideas of world harmony. Baltimore: John Hopkins University Press.

Steege, B. (2012). Helmholtz and the modern listener. Cambridge: Cambridge University Press.

Sterne, J. (2003). The audible past: Cultural origins in sound reproduction. Durham: Duke University Press.

Suisman, D. \& Strasser, S. (Eds.). (2010). The sound in the age of mechanical reproduction. Philadelphia: University of Pennsylvania Press.

Luís Cláudio Ribeiro is professor of Sound Culture and head of Communication Sciences Department at Lusófona University, in Lisbon. His Ph.D. in Communication Sciences developed research activity in the field of media epistemology and sound. His recent publications focus on the medium, identification and characterization of changes by the use of sound mediators in contemporary society. He is the main investigator of the projects Lisbon SoundMap, (FCT-2011-2014); The Technique and the Media as a Problem: from representation to thought (2017-18) and Aural Experience, Territory, and Community (FCT-2018-2021). In addition to the academic activity, he is also a poet and novelist.

The editorial and publishing process of this publication has been financed by the Ministry of Science and Higher Education from the funds for the dissemination of research (DUN) within the framework of publishing activity, contract no. 711/P-DUN/2019, period of implementation: the years 2019-2020. 